\title{
INFLUÊNCIA DA ÁGUA E DO POTÁSSIO NA QUALIDADE DA SEMENTE DE MAMOEIRO ${ }^{1}$
}

\author{
ROBSON CELESTINO MEIRELES ${ }^{2}$, ROBERTO FERREIRA DA SILVA ${ }^{3}$, EDUARDO FONTES ARAUJO ${ }^{4}$, \\ LUCILÉA SILVA DOS REIS ${ }^{5}$, ALBANISE BARBOSA MARINHO ${ }^{6}$, GUILHERME BASTOS LYRA ${ }^{6}$
}

\begin{abstract}
RESUMO - O objetivo do presente trabalho foi verificar o efeito da adubação potássica e das diferentes lâminas de irrigação sobre a germinação e o vigor das sementes de mamoeiro. Foram utilizadas sementes provenientes de frutos hermafroditas de mamoeiro do grupo Solo (cv. Golden), colhidos no estádio dois de maturação, na Fazenda Santa Terezinha, pertencente a Caliman Agrícola, localizada no município de Linhares - ES. Após a colheita, os frutos permaneceram armazenados por oito dias em local aberto e arejado. Os tratamentos foram constituídos por cinco lâminas de irrigação equivalentes a 70, 90,110, 130 e 150\% da evapotranspiração de referência e quatro doses de potássio (30, 42, 54 e 66g/planta), aplicadas mensalmente até o término do experimento. O espaçamento utilizado foi de, respectivamente, $3,6 \mathrm{~m}$ e 2,0m para as fileiras duplas e simples e a distância entre as plantas dentro das fileiras foi de $1,8 \mathrm{~m}$. As características avaliadas foram germinação e vigor, este último determinado pela primeira contagem do teste de germinação e pela classificação de plântulas. $\mathrm{O}$ delineamento estatístico utilizado foi o inteiramente casualizado, sendo os dados submetidos à análise de variância e regressão. A dose de $35 \mathrm{~g}$ de potássio associada à irrigação equivalente a $70 \%$ da evapotranspiração propiciou os maiores valores de germinação e que a combinação adequada da dose de potássio e lâmina de irrigação contribuiu de maneira significativa para o aumento do vigor das sementes de mamoeiro.
\end{abstract}

Termos para indexação: nutriente, germinação, vigor.

INFLUENCE OF THE WATER AND POTASSIUM IN THE QUALITY OF PAPAYA SEEDS.

ABSTRACT - The purpose of this work is to verify the effect of potassium fertilizing and the different irrigation levels on the germination and vigor of papaya tree seeds. To do so, it was used seeds coming from hermaphrodites fruits of the papaya tree, belonging to the group of Solo (cv. Golden), harvested during the stage two of maturing, in Santa Terezinha Farm, which belongs to Caliman Agrícola, localized in Linhares-ES. After harvesting, fruits were stored over eight days, in an open and aerated place. The treatments were constituted by five irrigation levels, equivalent to 70, 90, 110, 130 and $150 \%$ of the reference evapotranspiration and four doses of potassium $(30,42,54$, and $66 \mathrm{~g} / \mathrm{plant})$, applied monthly, until the end of the experiment. The spacing used was, respectively, 3,6 meters and 2 meters for double-rows and single-rows, and the plants distance in the rows was 1,8 meters. The assessed characteristics were germination and vigor, which was determined by germination

\footnotetext{
${ }^{1}$ Aceito em 19/11/2007. Publicado em 20/08/2008.

${ }^{2}$ Parte de tese de doutorado em Produção Vegetal na Universidade Estadual do Norte Fluminense "Darcy Ribeiro".

${ }^{2}$ Doutorando em Produção Vegetal - UENF - Campos dos Goytacazes, RJ. robmeireles@hotmail.com

${ }^{3}$ Professor Titular - UENF - Campos dos Goytacazes, RJ. Roberto@uenf.br
}

${ }^{4}$ Professor Departamento de Fitotecnia - UFV, efaraujo@ufv.br

${ }^{5}$ Doutoranda em Genética e Melhoramento de Plantas - UENF, lucileasreis@, yahoo.com.br

${ }^{6}$ Doutor (a) em Produção Vegetal - UENF - Campos dos Goytacazes, RJ. 
test first count and by seedling classification. The experimental design was completely randomized, having the data been submitted to variance and regression analysis. From the obtained results, it was possible to conclude that the $35 \mathrm{~g}$ of potassium dose associated to irrigation, equivalent to $70 \%$ of evapotranspiration increased germination percentage, and that the suitable combination of potassium dose and irrigation levels contributed significantly to the increase of papaya tree seeds vigor.

Indexs terms: nutrient, germination, vigor.

\section{INTRODUÇÃO}

A produção de sementes de alta qualidade é resultante de um conjunto favorável de fatores, onde o emprego de solos com níveis de fertilidade satisfatórios constitui item decisivo, uma vez que a boa fertilidade, além de proporcionar incremento na produção também pode contribuir para a boa formação das sementes. Assim, Carvalho e Nakagawa (2000) afirmam que a planta bem nutrida está em condições de produzir elevado número de sementes bem formadas.

É durante a fase de formação das sementes que a exigência nutricional torna-se mais crítica, pois é neste estádio de desenvolvimento que considerável quantidade de nutrientes é translocada para as mesmas. A ocorrência deste ponto crítico de exigência nutricional deve-se ao fato de os minerais serem essenciais para a formação e o desenvolvimento de novos órgãos e no acúmulo de material de reserva (Carvalho e Nakagawa, 2000). Para Sá (1994) os nutrientes apresentam papel relevante durante as fases de formação, desenvolvimento e maturação das sementes, principalmente na constituição das membranas celulares e no acúmulo de lipídios, carboidratos e proteínas.

Com relação aos estudos que envolvem a qualidade das sementes, o potássio merece papel de destaque, visto que dentre as suas funções na planta, esse nutriente está diretamente envolvido no desenvolvimento das sementes, principalmente por atuar na formação de amidos e açúcares, no vigor das plantas, propiciando melhores colheitas. Além disso, a sua deficiência poderá acarretar decréscimos na produção e enrugamento das sementes (Fontes, 2001).

Além do aspecto nutricional, a água também é fator essencial para a fase de desenvolvimento das sementes, sendo o principal veículo responsável pela translocação dos fotoassimilados produzidos nas áreas consideradas fontes da planta para as regiões consideradas drenos, neste caso as sementes. Isto justifica os elevados teores de água na semente durante a fase do intenso acúmulo de matéria seca (Carvalho e Nakagawa, 2000).
A água é também fundamental para a iniciação floral e desenvolvimento das flores e inflorescências, período em que o número potencial de sementes é determinado. No período de fertilização, quando o potencial de produção é fixado, a água torna-se importante para evitar a desidratação do grão de pólen e garantir o desenvolvimento e a penetração do tubo polínico e com isso garantir maior número de frutos e sementes (Magalhães et al, 1995).

Sendo a água fator limitante no desenvolvimento da planta, a prática da irrigação se faz necessária para que as culturas tenham equilíbrio quanto à utilização da água, de modo a não comprometer os processos de absorção, bem como as suas reações químicas (Taiz e Zeiger, 2004).

Deste modo, o objetivo deste trabalho foi verificar o efeito da adubação potássica, em diversas doses, associada às diferentes lâminas de irrigação sobre a qualidade fisiológica das sementes do mamoeiro.

\section{MATERIAL E MÉTODOS}

O experimento de campo foi instalado na Fazenda Santa Terezinha pertencente à Empresa Caliman Agrícola Ltda, localizada no município de Linhares, região Norte do estado do Espírito Santo. As análises de laboratório foram conduzidas no Setor de Produção e Tecnologia de Sementes do Laboratório de Fitotecnia (LFIT) da Universidade Estadual do Norte Fluminense Darcy Ribeiro (UENF) em Campos dos Goytacazes - RJ.

Foram utilizadas sementes provenientes de frutos hermafroditas de mamoeiro do grupo Solo (cv. Golden), colhidos no estádio dois de maturação. Antes do processo de extração das sementes, os frutos permaneceram armazenados em condição ambiente por oito dias.

As sementes foram extraídas e lavadas manualmente para remoção da sarcotesta, utilizando-se uma peneira de arame e água corrente. Após esse procedimento, as sementes foram submetidas à secagem em secador regulado a $37^{\circ} \mathrm{C} \mathrm{e}$ velocidade do ar igual a $1,2 \mathrm{~m} / \mathrm{s}^{-1}$ até que fosse atingido teor 
de água de 7\% (base úmida).

Os tratamentos foram constituídos por cinco lâminas de irrigação equivalentes a 70,90,110, 130 e 150\% da evapotranspiração de referência, estimada pela equação de Penman-Monteith (FAO-56) e quatro doses de potássio (30, 42,54 e $66 \mathrm{~g}$ ) por planta por mês. Utilizaram-se fileiras duplas com espaçamento de $2 \mathrm{~m}$ entre fileiras e $1,80 \mathrm{~m}$ entre plantas. A distância utilizada entre as fileiras duplas foi de $3,60 \mathrm{~m}$, totalizando uma área de $5,04 \mathrm{~m}^{2}$ por planta e de $120,96 \mathrm{~m}^{2}$ por parcela.

As características avaliadas foram germinação e vigor, este último obtido pela primeira contagem do teste de germinação e pela classificação de plântulas. Germinação empregando como substrato o papel germitest, umedecido com água destilada na proporção de 2,5 vezes o peso do papel seco, foram utilizadas quatro subamostras com 50 sementes por repetição, os quais foram mantidos em germinador do tipo BOD com temperatura alternada de $20-30^{\circ} \mathrm{C}$ (16h de escuro e 8 h de luz) por 30 dias. Após este período, foi realizada a avaliação das plântulas normais conforme prescrito nas Regras para Análise de Sementes (RAS), sendo os resultados expressos em porcentagem de plântulas normais (Brasil, 1992); Primeira contagem de germinação - Executado em conjunto ao teste de germinação, sendo considerada como germinada, a semente que no $15^{\circ}$ dia após a instalação do teste apresentava protrusão da raiz primária. $\mathrm{O}$ vigor foi expresso pela porcentagem das sementes que emitiram raiz; Classificação do vigor de plântulas - As plântulas normais foram avaliadas de acordo com o seu vigor, sendo classificadas como plântulas normais fortes, quando, além de apresentarem todas as estruturas essenciais, destacavamse das demais por seu maior tamanho e vigor de raiz e parte aérea (aproximadamente $5 \mathrm{~cm}$ ). Desse modo, os resultados de vigor foram expressos pela porcentagem de plântulas normais fortes avaliados no $15^{\circ}$ e no $30^{\circ}$ dia do teste de germinação (Martins et al., 2005).

O delineamento estatístico utilizado foi o inteiramente casualizado, sendo os dados submetidos à análise de variância e regressão linear, quadrática e cúbica, de modo que o modelo escolhido foi aquele que melhor se ajustou aos dados obtidos.

\section{RESULTADOS E DISCUSSÃO}

De acordo com a avaliação por ocasião da primeira contagem de germinação, pode-se observar que a dose de $30 \mathrm{~g}$ de potássio associado com a lâmina de irrigação equivalente a $70 \%$, foi a que proporcionou os maiores valores de vigor, conforme pode ser observado na Figura 1.

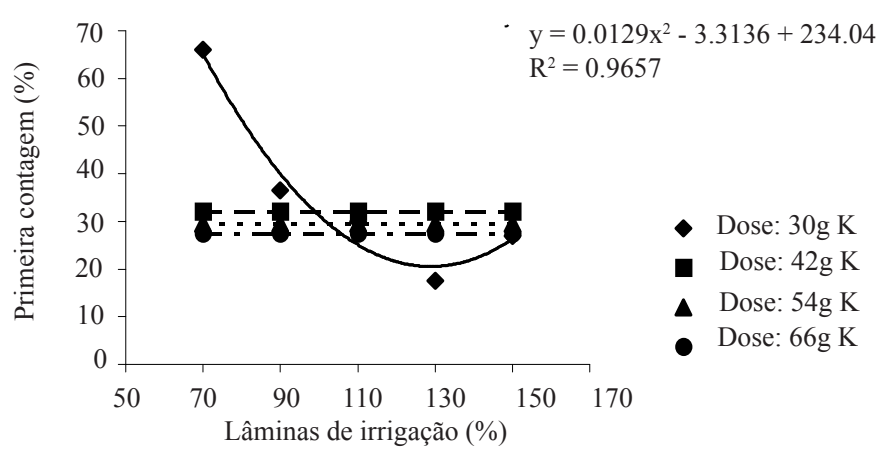

\section{FIGURA 1. Vigor, pelo teste de primeira contagem de germinação, de sementes de mamoeiro em função de cinco lâminas de irrigação e quatro doses de potássio.}

Nakagawa et al. (2001), verificando o efeito da adubação potássica sobre a qualidade fisiológica das sementes de aveiapreta, utilizaram três doses de $\mathrm{K}_{2} \mathrm{O}$, disponibilizado por meio do adubo químico cloreto de potássio, nas seguintes doses: zero; 20 e $40 \mathrm{~kg} / \mathrm{ha}$. Concluíram, no entanto, que a dose de $20 \mathrm{~kg} / \mathrm{ha}$, embora não sendo a maior, foi suficiente para proporcionar melhoria sobre a produtividade e a qualidade das sementes.

Resultados expressivos da aplicação de potássio sobre a qualidade fisiológica das sementes também tem sido encontrada para outras culturas. Prado (2004) trabalhando com a cultura do feijoeiro constatou que a aplicação de potássio, principalmente quando disponibilizada no início da instalação da lavoura, aumentou o poder germinativo e o vigor das sementes produzidas, além de provocar decréscimo no nível de Phomopsis sp, melhorando com isso a qualidade sanitária das mesmas.

Para as demais doses de potássio é possível notar que não foi possível o ajuste da equação de regressão dentro das lâminas de irrigação, sendo o fator $\mathbf{y}$ igual à média de cada uma das doses.

Na Figura 2, observa-se que a dose de $30 \mathrm{~g}$ de potássio associado à lâmina de irrigação equivalente a 70\% proporcionou valores equivalentes a $75 \%$ de germinação. No entanto, à medida que foram aumentadas as lâminas de irrigação verificou-se decréscimo na porcentagem de germinação, de modo que para na lâmina de $150 \%$ a germinação foi inferior a $50 \%$, o que determinou decréscimo 
de $20 \%$ em relação à lâmina equivalente a 70\%.

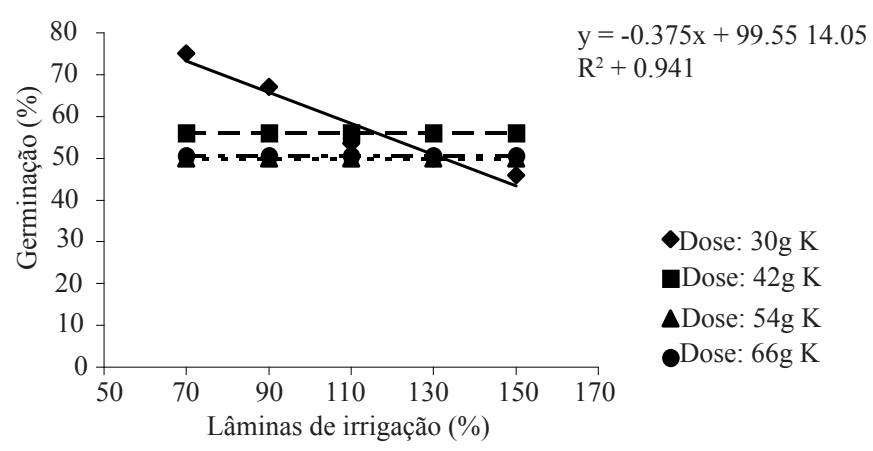

FIGURA 2. Germinação de sementes de mamoeiro em função de cinco lâminas de irrigação e de quatro doses de potássio.

É provável que as menores lâminas de irrigação tenham permitido maior absorção de potássio pela planta e que o mesmo tenha contribuído com a qualidade fisiológica da semente, pois Almeida et al. (2002) aplicando sete lâminas de irrigação em plantas de mamoeiro, constataram que as equações de regressão geradas para a maioria dos nutrientes encontrados nas folhas em função da irrigação foram lineares, sendo que os valores de potássio, nitrogênio e ferro decresceram de maneira linear à medida que aumentou a disponibilidade de água para a cultura. Em razão da constatação de variação para a maioria dos nutrientes com relação às diferentes lâminas de irrigação disponibilizadas para a cultura do mamoeiro, esses mesmos autores concluíram que é necessário que se faça ajuste da adubação em função das lâminas de água.

Diante dos resultados, observou-se que a lâmina de irrigação equivalente a $70 \%$ da evapotranspiração de referência para a cultura do mamoeiro não deve ser considerada crítica para a produção de sementes com qualidade, uma vez que, mesmo havendo menor disponibilidade de água para a cultura com relação a demais lâminas aplicadas, a referida lâmina propiciou o máximo de qualidade.

Para as demais doses, observa-se que os valores de germinação não foram alterados de acordo com o aumento das lâminas de irrigação. Entretanto, a dose de $42 \mathrm{~g}$ de potássio propiciou germinação superior às doses de 54 e $66 \mathrm{~g}$ de potássio, indicando que as plantas de mamoeiro utilizadas no experimento produzem sementes de maior poder germinativo quando aplicada as menores dose do nutriente associada à menor lâmina de irrigação.
Para vários autores a deficiência hídrica pode influenciar de maneira negativa a produtividade e a qualidade fisiológica das sementes, como Crusciol et al. (1999) que verificaram, para a cultura do arroz, que a deficiência hídrica pode proporcionar decréscimo na germinação e no vigor das sementes, quando comparados cultivos de sequeiro com sistema de irrigação por aspersão.

Do mesmo modo, Crusciol et al. (2001) trabalhando com plantas de arroz, verificaram que a qualidade das sementes produzidas foi prejudicada à medida que a lâmina de irrigação disponibilizada para a cultura foi aumentada.

Na Figura 3 é possível constatar que embora não tenha ocorrido diferença significativa na regressão para lâminas de irrigação nas doses de 42, 54 e $66 \mathrm{~g}$ de potássio, a dose de $42 \mathrm{~g}$ proporcionou a maior média de plântulas fortes, indicando que é possível utilizar esta dose de potássio associada a menor lamina de irrigação, o que resultaria em um manejo mais racional e econômico. Observa-se ainda que, para a dose de $30 \mathrm{~g}$ de potássio, houve acréscimo no vigor das sementes à medida que se aumentou a irrigação, sendo que máximo vigor foi observado para a lâmina de $150 \%$. Contudo, o mesmo foi também obtido para a lâmina de $70 \%$, quando a dose empregada foi a de $66 \mathrm{~g}$.

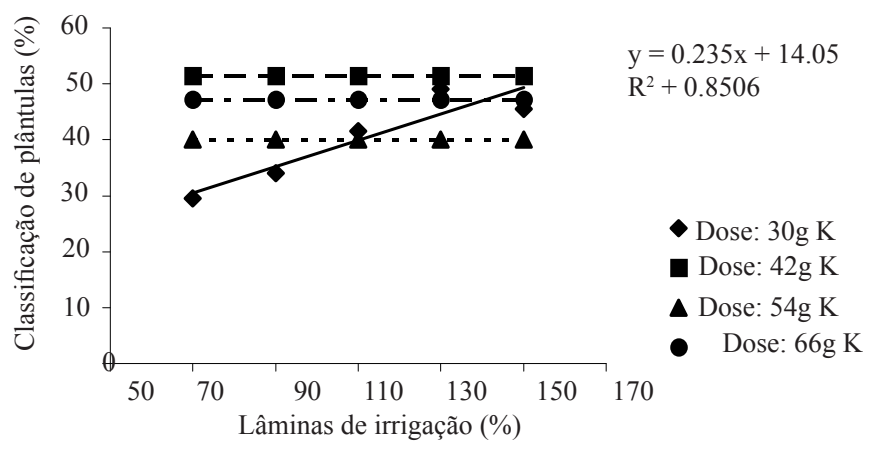

FIGURA 3. Vigor, pelo teste de classificação do vigor de plântulas, de mamoeiro em função de cinco lâminas de irrigação e de quatro doses de potássio.

A ação do potássio tem sido relacionada de maneira positiva com a qualidade das sementes de muitas espécies. $\mathrm{Na}$ cultura da canola (Brassica napus L.) experimentos com este nutriente permitiram verificar o efeito positivo do potássio sobre o peso de mil sementes, a resistência ao desenvolvimento de certas doenças comuns à cultura, à germinação e crescimento das plântulas (Sharma e Kolte, 
1994). Para Ávila et al. (2004), a adubação com potássio, nessa mesma cultura, além de proporcionar melhoria na qualidade fisiológica e sanitária das sementes, contribuiu para o aumento da produtividade.

\section{CONCLUSÕES}

- A dose de $30 \mathrm{~g}$ de potássio associada à irrigação equivalente a $70 \%$ da evapotranspiração propiciou os maiores porcentuais de germinação.

- A associação de dose de potássio com lâmina de irrigação adequada contribui de maneira significativa para o aumento do vigor das sementes de mamoeiro.

\section{REFERÊNCIAS}

ALMEIDA, F.T.; BERNARDO, S.; MARINHO, C.S.; MARIN, S.L.D.; SOUZA, E.F. Teores de nutrientes do mamoeiro 'improved sunrise solo 72/12' sob diferentes lâminas de irrigação, no norte fluminense. Revista Brasileira de Fruticultura, v.24, n.2, p.547-551, 2002.

ÁVILA, M.R.; BRACCINI, A.L.; SCAPIM, C.A.; ALBRECHT, L.P. Adubação potássica em canola e seu efeito no rendimento e na qualidade fisiológica e sanitária das sementes. Acta Scientiarum Agronomy, v.26, n.4, p.457-481, 2004.

BRASIL. Ministério da Agricultura e Reforma Agrária. Secretaria Nacional de Defesa Sanitária. Departamento Nacional de Defesa Vegetal. Coordenação de Laboratório vegetal. Regras para análise de sementes. Brasília, DF: SNDA/DNDV/CLAV, 1992. 365p.

CARVALHO, N.M.; NAKAGAWA, J. Sementes: ciência, tecnologia e produção. Campinas. Fundação Cargil, 2000. $588 \mathrm{p}$.

CRUSCIOL, C.A.C.; ARF, O.; ZUCARELI, C.; E, C.; SÁ, M.E.; NAKAGAWA, J. Produção e qualidade fisiológica de sementes de arroz de terras altas em função da disponibilidade hídrica. Revista Brasileira de Sementes, v.23, n.2, p.287-
293, 2001.

CRUSCIOL, C.A.C.; MACHADO, J.R.; SÁ, M.E.; ARF, O.; RODRIGUES, R.A.F. Efeito de lâminas de água na produtividade e na qualidade fisiológica de sementes de arroz (Oryza sativa L.) com irrigação por aspersão. Informativo ABRATES, v.9, n.1/2, p.56 , 1999. Número especial [Resumos] XI Congresso Brasileiro de Sementes, 1999, Foz do Iguaçu.

FONTES, P.C.R. Diagnóstico do estado nutricional das plantas. Viçosa: UFV, 2001. 122p.

MAGALHÃES, P.C.; DURÃES, F.O.M.; PAIVA, E. Fisiologia da planta de milho. Sete lagoas: EMBRAPACNPMS, 1995. 27p. (EMBRAPA-CNPMS. Circular Técnica, 20).

MARTINS, G.N.; SILVA, R.F.; ARAÚJO, E.F.; PEREIRA, M.G.; VIEIRA, H.D.; VIANA, A.P. Influência do tipo de fruto, peso específico das sementes e período de armazenamento na qualidade fisiológica de sementes de mamão do grupo formosa. Revista Brasileira de Sementes, v.27, n.2, p.12 $-17,2005$.

NAKAGAWA, J.; CAVARIANI, C.; BICUDO, S.J. Produção e qualidade de sementes de aveia-preta em função da adubação fosfatada e potássica. Revista Brasileira de Sementes, v.23, n.1, p.260-266, 2001.

PRADO, R.M. Estado nutricional da semente repercute na sua qualidade. Seed News, v.8, n.4, p.18-21, 2004.

SÁ, M.E. Importância da adubação na qualidade de semente. In: SÁ, M.E.; BUZZETI, S. (Ed.). Importância da adubação na qualidade dos produtos agrícolas. São Paulo: Ícone, 1994. p.65-98.

SHARMA, S.R.; KOLTE, S.J. Effect of soil applied NPK fertilizers on severity of black spot disease (Alternaria brassicae) and yield of oilseed rape. Plant Soil, v.167, p.313320, 1994.

TAIZ, L.; ZEIGER, E. Fisiologia vegetal. 3.ed. Porto Alegre: Artmed, 2004, 719p. 